\title{
Minimizing Synaptic Depression by Control of Release Probability
}

\author{
Stephan Brenowitz ${ }^{1,2}$ and Laurence 0. Trussell ${ }^{2}$ \\ ${ }^{1}$ Neuroscience Training Program, University of Wisconsin, Madison, Wisconsin 53706, and ${ }^{2}$ Oregon Hearing Research \\ Center and Vollum Institute, Oregon Health Sciences University, Portland, Oregon 97201
}

Transmission at the end-bulb synapse formed by auditory nerve terminals onto the soma of neurons in the avian nucleus magnocellularis is characterized by high transmitter release probability and strong synaptic depression. Activation of presynaptic $\mathrm{GABA}_{\mathrm{B}}$ receptors minimizes depression at this synapse and significantly enhances synaptic strength during high-frequency activity. Here we investigate synaptic mechanisms underlying this phenomenon. EPSC amplitudes evoked by $200 \mathrm{~Hz}$ trains increased more than twofold when release probability was reduced with $\mathrm{Cd}^{2+}$ or baclofen. This effect was not exhibited by a transmitter depletion model of presynaptic depression, which predicts that EPSC amplitudes reach a common steady-state amplitude during high-frequency trains, despite alterations of initial release probability. However, an additional source of postsynaptic depression was sufficient to explain our findings. Aniracetam, a modulator of AMPA receptors that reduces desensitization, decreased the amount of synaptic depression during trains, indicating that desensitization occurred during

Synaptic strength varies with the frequency of synaptic activity as a consequence of several forms of short- and long-term plasticity (Feng, 1940; Lundberg and Quilisch, 1953; DelCastillo and Katz, 1954; Kusano and Landau, 1975). Synaptic depression is the predominant form of short-term plasticity at synapses with high probability of transmitter release (Zucker, 1989) and has generally been attributed to depletion of a pool of readily releasable transmitter vesicles (Takeuchi, 1958; Thies, 1965; Betz, 1970; Dobrunz and Stevens, 1997; Wu and Borst, 1999). Depression is especially pronounced in large synapses of the auditory pathway. In the avian nucleus magnocellularis (nMag), action potentials in the auditory nerve evoked at low frequency $(<1 \mathrm{~Hz})$ generate large AMPA-mediated EPSCs (Zhou and Parks, 1992), resulting from release of 100-200 transmitter quanta onto soma of the postsynaptic nMag neurons (Zhang and Trussell, 1994a). However, mean firing rates of auditory nerve fibers in vivo range from 86 to $327 \mathrm{~Hz}$ (Warchol and Dallos, 1990; Salvi et al., 1992). At these frequencies, synaptic responses exhibit pronounced depression sufficient to reduce single-fiber EPSPs below action potential threshold, eventually interrupting the relay of timing information required for sound localization (Zhang and Trussell, 1994b; Brenowitz et al., 1998).

\footnotetext{
Received Oct. 18, 2000; revised Dec. 7, 2000; accepted Dec. 22, 2000.

This work was supported by National Institutes of Health Grants NS28901 (L.O.T.) and GM07507 (S.B.). We thank Drs. V. Alvarez, J. Diamond, R. Fettiplace, T. Lu, I. Raman, and R. Turecek for helpful discussions and comments on this manuscript.

Correspondence should be addressed to Stephan Brenowitz, Auditory Neuroscience L-335A, Oregon Health Sciences University, 3181 SW Sam Jackson Park Road, Portland, OR 97201. E-mail: brenowit@ohsu.edu.

Copyright (C) 2001 Society for Neuroscience 0270-6474/01/211857-11\$15.00/0
}

trains of stimuli. However, this effect of aniracetam was absent when release probability was lowered with baclofen or $\mathrm{Cd}^{2+}$. No effect of aniracetam on the NMDA component of the EPSC was seen, confirming a postsynaptic site of action of aniracetam. When desensitization was reduced with aniracetam, steady-state EPSC amplitudes during trains were found to converge over a wide range of release probabilities, as predicted by the depletion model. Additional evidence of AMPA receptor desensitization was provided by direct measurement of quantal amplitudes immediately after stimulus trains. Thus, presynaptic modulation by $\mathrm{GABA}_{\mathrm{B}}$ receptors regulates the extent of AMPA receptor desensitization and controls synaptic strength, thereby modulating the flow of information at an auditory synapse.

Key words: short-term depression; AMPA receptors; desensitization; cochlear nucleus; $G A B A_{B}$ receptors; end-bulb synapse; auditory

$\mathrm{GABA}_{\mathrm{B}}$ receptors located on end-bulb terminals of auditory nerve fibers modulate synaptic strength in nMag in a frequencydependent manner. Activation of presynaptic $\mathrm{GABA}_{\mathrm{B}}$ receptors reduces glutamate release by $85 \%$ during low-frequency auditory nerve activity (Otis and Trussell, 1996). However, at high rates of auditory nerve activity (up to $500 \mathrm{~Hz}$ ), $\mathrm{GABA}_{\mathrm{B}}$ receptor activation increases the steady-state amplitudes of synaptic responses up to fivefold relative to control, by lowering initial transmitter release and slowing onset of depression during stimulus trains (Brenowitz et al., 1998). Because the enhancement of synaptic strength by $\mathrm{GABA}_{\mathrm{B}}$ receptor activation allowed suprathreshold transmission to persist longer during high-frequency trains, this mechanism may play an important role in allowing faithful relaying of ongoing auditory stimuli. This finding was unexpected, because presynaptic depletion models of depression indicate that, during high-frequency stimulation, response amplitudes reach a steady state determined by the rates of transmitter release and vesicle recycling but not by the initial transmitter release probability $\left(P_{\mathrm{R}}\right)$ (O’Donovan and Rinzel, 1997; Tsodyks and Markram, 1997). Thus, alterations in $P_{\mathrm{R}}$ are not expected to affect steadystate EPSC amplitudes $\left(\right.$ EPSC $\left._{\mathrm{SS}}\right)$ during high-frequency trains. Convergence of steady-state EPSC amplitudes evoked at high frequency, despite changes in $P_{\mathrm{R}}$, has been confirmed in cortical (Markram and Tsodyks, 1996; Abbott et al., 1997) and cerebellar (Kreitzer and Regehr, 2000) synapses.

Previous studies of nMag have characterized AMPA receptor desensitization to applied glutamate or to single synaptic stimuli (Trussell et al., 1993; Raman and Trussell, 1995a; Otis et al., 1996b). Here we describe a component of synaptic depression 
that persists during repetitive stimulation of the end-bulb synapse and was attributed to receptor desensitization. Decreasing $P_{\mathrm{R}}$ by activation of presynaptic $\mathrm{GABA}_{\mathrm{B}}$ receptors or with $\mathrm{Cd}^{2+}$ reduced or eliminated the contribution of desensitization. After reduction of desensitization with aniracetam, lowering $P_{\mathrm{R}}$ no longer caused enhancement of steady-state EPSC amplitudes during high-frequency trains. Instead, EPSCs reached the same steady-state amplitude despite large changes in release probability. These findings suggest that, during periods of high-frequency activity, synaptic depression was enhanced under high but not low $P_{\mathrm{R}}$ conditions. Thus, activation of presynaptic $\mathrm{GABA}_{\mathrm{B}}$ receptors may control synaptic strength by regulating the extent of AMPA receptor desensitization.

\section{MATERIALS AND METHODS}

Physiology. Brainstem slices (300 $\mu \mathrm{m})$ were prepared from embryonic day 17-20 chicks (Zhang and Trussell, 1994a; Turecek and Trussell, 2000). During dissection, storage, and recording, slices were maintained in warmed, oxygenated saline containing (in $\mathrm{mM}$ ): $140 \mathrm{NaCl}, 20$ glucose, 10 HEPES, $5 \mathrm{KCl}, 3 \mathrm{CaCl}_{2}$, and $1 \mathrm{MgCl}_{2}, \mathrm{pH}$ 7.35. During recordings $\left(34-37^{\circ} \mathrm{C}\right)$, slices were perfused at $3-5 \mathrm{ml} / \mathrm{min}$. Neurons were viewed with a Zeiss (Oberkochen, Germany) Axioskop and Olympus Optical (Tokyo, Japan) $60 \times$ water immersion lens using differential interference contrast optics and infrared illumination. For measurement of AMPAmediated EPSCs, saline was supplemented with (in $\mu \mathrm{M}$ ): 100 DL-APV, 10 7-Cl-kynurenate, 10 SR-95531, and 2 strychnine. In other experiments, NMDA-mediated EPSCs were pharmacologically isolated by supplementing saline with (in $\mu \mathrm{M}$ ): 20 GYKI-52466, 20 6,7-dinitro-7quinoxaline-2,3-dione (DNQX), 20 SR-95531, 20 glycine, and 2 strychnine. Neurons were voltage clamped with an Axopatch 200A or 200B amplifier (Axon Instruments, Foster City, CA) at $-30 \mathrm{mV}$ (for recording AMPA receptor-mediated EPSCs), $+50 \mathrm{mV}$ (for recording NMDA receptor-mediated EPSCs), or $-60 \mathrm{mV}$ [for recording miniature synaptic currents (mEPSCs)]. Electrode series resistance (2-8 M $\Omega$ ) was compensated $80-95 \%$. Pipettes were filled with an intracellular solution containing (in $\mathrm{mM}$ ): $125 \mathrm{CH}_{3} \mathrm{O}_{3} \mathrm{SCs}$ (Cs-methanesulfonate), $15 \mathrm{CsCl}, 10$ HEPES, 5 BAPTA, and $1 \mathrm{MgCl}_{2}, \mathrm{pH}$ 7.25. For measurement of NMDA responses, $2 \mathrm{Na}_{2}$-ATP was added to the pipette solution. Synaptic responses were obtained by positioning a stimulus electrode (2-4 M $\Omega$ ) onto nearby myelinated fibers $20-100 \mu \mathrm{m}$ from the postsynaptic cell body. Individual afferent auditory nerve axons were stimulated by $100-$ $200 \mu \mathrm{sec}, 5-50 \mathrm{~V}$ pulses delivered via an isolated stimulus unit (Iso-flex; A.M.P.I., Jerusalem, Israel). Currents were filtered at $5-10 \mathrm{kHz}$ and sampled at $20 \mathrm{kHz}$. Aniracetam stocks $(0.5 \mathrm{M}, 100 \times)$ were prepared in DMSO and added to extracellular solutions immediately before use. The final working concentration of aniracetam was $5 \mathrm{~mm}$ and aniracetamcontaining solutions included $1 \%$ (v/v) DMSO. For all experiments using aniracetam, control extracellular solutions were also supplemented with $1 \%$ DMSO. Baclofen and $\mathrm{Cd}^{2+}$ were either added to extracellular solutions or pressure applied with a puffer pipette (2-4 $\mu \mathrm{m}$ tip diameter). Means are reported \pm SE. Chemicals and drugs were obtained from Sigma (St. Louis, MO), Research Biochemicals (Natick, MA), and Tocris Cookson (Ballwin, MO).

mEPSC analysis. Frequency of spontaneous mEPSCs was enhanced by addition of $\mathrm{SrCl}_{2}(2-4 \mathrm{~mm})$ to extracellular solutions. Whole-cell currents were digitally sampled on a second channel using a Cygnus (Medina, OH) FLA-01 signal conditioner to increase gain $10 \times$. mEPSCs were detected using derivative or template detection algorithms implemented in Axograph software (Axon Instruments).

Modeling synaptic depression. For simulations of synaptic depression, the model consisted of a synapse with $N_{0}$ release sites, each of which releases a vesicle with probability $P_{\mathrm{R}}$ after a presynaptic action potential. Immediately after release, sites become refractory and subsequently recover with a single-exponential time course, $\tau_{\mathrm{D}}$. This value is assumed to be $\mathrm{Ca}^{2+}$-independent. Before the first stimulus,

$$
N_{1-}=N_{0} \text {. }
$$

This notation was used by Weis et al. (1999), where $N_{1-}$ refers to the releasable pool size immediately before stimulus 1 , and $N_{1+}$ refers to the releasable pool size after stimulus 1 . Thus,

$$
N_{1+}=\left(1-P_{\mathrm{R}}\right) \cdot N_{0}
$$

After recovery during the interval between the first and second stimuli,

$$
N_{2-}=\left(1-P_{\mathrm{R}}\right) \cdot N_{0}+P_{\mathrm{R}} \cdot N_{0} \cdot \exp \left(-\mathrm{int} / \tau_{\text {rec }}\right),
$$

where int is the interval between stimuli and $t_{\mathrm{rec}}$ is the exponential time constant for the transition of release sites from a refractory to an active state. This model was iteratively calculated for stimulus trains of arbitrary lengths.

Desensitization is modeled using a coefficient, $\beta$, that scales quantal amplitudes uniformly at all release sites. The amount of desensitization induced by each EPSC is modeled as having an exponential relationship to the quantal content:

$$
\beta\left(m_{\mathrm{i}}\right)=1-A \cdot\left(m_{\mathrm{i}} / N_{0}\right)^{\mathrm{B}},
$$

where $\beta$ is the fraction of nondesensitized receptors, $m_{\mathrm{i}}$ is the quantal content of EPSC $\mathrm{E}_{\mathrm{i}}$, and parameters $A$ and $B$ define the function relating release and desensitization. $\beta$ recovers with a single-exponential time course between stimuli $\left(\tau_{\beta}\right)$. Before the first stimulus,

$$
\beta_{1-}=1
$$

Immediately after the first stimulus,

$$
\beta_{1+}=\beta\left(m_{1}\right)
$$

where $m_{1}$ is the quantal content of the first EPSC. Before the second stimulus,

$$
\beta_{2-}=\beta_{1+}+\left(1-\beta_{1+}\right) \cdot \exp \left(-\operatorname{int} / \tau_{\beta}\right)
$$

After the second stimulus, receptor availability is expressed as:

$$
\beta_{2+}=\beta_{2-} \cdot \beta\left(m_{2}\right) .
$$

The value of $\beta$ was calculated iteratively throughout the train. The amplitude of an EPSC on the $i$ th stimulus of a train using the desensitization model is:

$$
I=N_{\mathrm{i}-} \cdot P_{\mathrm{R}} \cdot q \cdot \beta_{\mathrm{i}-},
$$

where $q$ is the quantal amplitude. To obtain values for parameters in the model, simulations were compared with data in Figure $4 B$. First, the purely presynaptic depression model was fit to data obtained in aniracetam. This yielded values of $P_{\mathrm{R}}=0.65$ and $\tau_{\text {rec }}=75 \mathrm{msec}$. Parameters affecting desensitization were then determined by fitting the model to the control data in Figure $4 B$, yielding values $A=0.90, B=1.5$, and $\tau_{\beta}=100 \mathrm{msec}$.

\section{RESULTS}

\section{Enhancement of synaptic strength by reducing release probability}

Stimulation of auditory nerve fibers at $200 \mathrm{~Hz}$ evoked large inward currents in nMag neurons voltage clamped at a holding potential of $-30 \mathrm{mV}$. During stimulus trains, the average amplitude of the first EPSC was $-8.11 \pm 0.62 \mathrm{nA}$ and depressed to $7.1 \pm 2.2 \%$ of this value during trains of 10 stimuli $(n=6)$ (Fig. $1 A, B$; see Fig. $4 B$ ). As shown previously (Brenowitz et al., 1998), activation of presynaptic $\mathrm{GABA}_{\mathrm{B}}$ receptors by bath application of baclofen $(50 \mu \mathrm{M})$ reduced initial response amplitudes to $16 \pm 3 \%$ of control $(n=6)$. However, depression during $200 \mathrm{~Hz}$ trains was minimal in baclofen, so that after two to three stimuli, absolute EPSC amplitudes in baclofen were enhanced $215 \pm 35 \%$ relative to controls $(n=6)$ (Fig. 1 Aii, $C$, filled circles).

Because activation of presynaptic $\mathrm{GABA}_{\mathrm{B}}$ receptors with baclofen reduces $\mathrm{Ca}^{2+}$ currents (Bean, 1989; Dittman and Regehr, 1996; Wu and Saggau, 1997), we examined whether block of $\mathrm{Ca}^{2+}$ 
A i

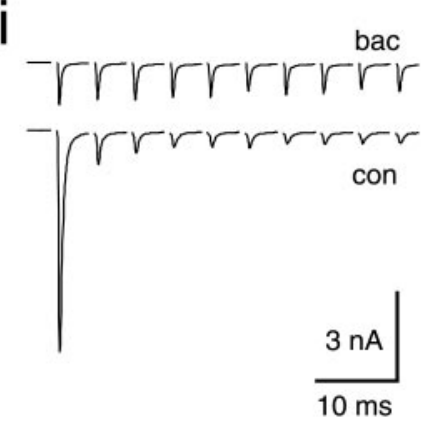

$\mathrm{Bi}$

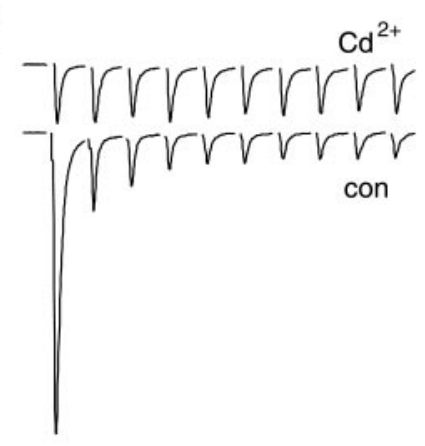

ii
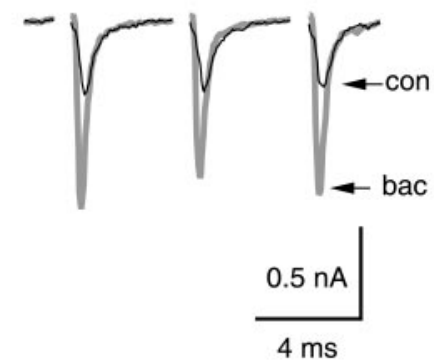

ii

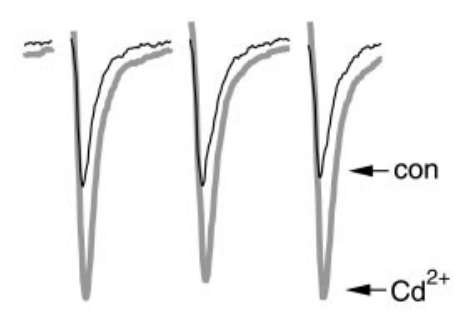

C

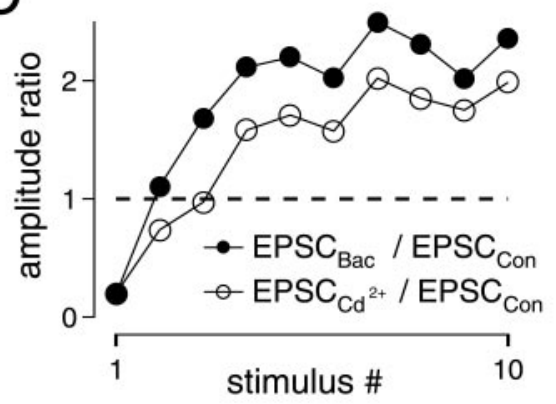

D

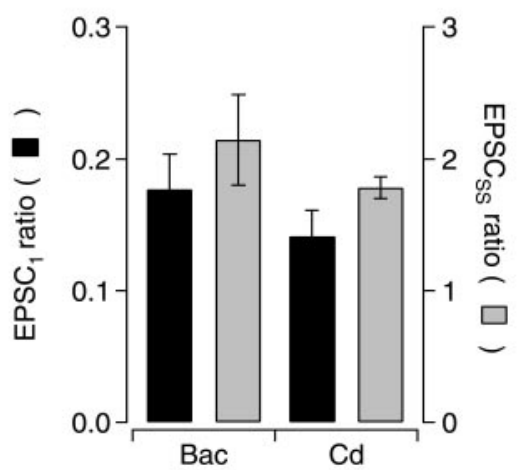

Figure 1. Enhancement of synaptic strength by lowering release probability. Ai, Trains of 10 EPSCs were evoked at $200 \mathrm{~Hz}$ under control conditions (bottom trace) or in the presence of $50 \mu \mathrm{M}$ baclofen (top trace). The first peak in baclofen was reduced to $19.3 \%$ of control. $V_{\mathrm{m}}=-30 \mathrm{mV}$. Averages of 5-10 trials are shown. Stimulus artifacts have been removed. Aii, EPSCs 8-10 have been enlarged to illustrate the increase in EPSC amplitudes when initial release probability was reduced with baclofen (control, black trace; baclofen, gray trace). Bi, Same as in $A$, but in the presence of Cd ${ }^{2+}(20 \mu \mathrm{M})$ (top trace). Peak of $\mathrm{EPSC}_{1}$ in $\mathrm{Cd}^{2+}$ was reduced to $20.1 \%$ of control. Bii, EPSCs 8-10 have been enlarged to illustrate enhancement of EPSC $\mathrm{SS}_{\mathrm{S}}$ in the presence of $\mathrm{Cd}^{2+}$ (control, black trace; $\mathrm{Cd}^{2+}$, gray trace). C, Filled circles show amplitude ratio of EPSCs in baclofen to controls for each stimulus. As the control EPSCs depress during the train, this value increases. Average enhancement of EPSCs for stimuli 8-10 in this cell was $223 \%$. Open circles show ratios of EPSCs in $\mathrm{Cd}^{2+}$ relative to controls. Average steady-state enhancement of EPSCs in this cell was $186 \%$. Data in $A-C$ are from two different

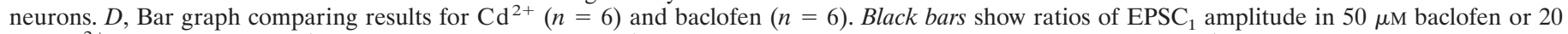
$\mu \mathrm{M} \mathrm{Cd}^{2+}$ relative to control (EPSC $1, \mathrm{BAC}_{\text {(or Cd) }} /$ EPSC $_{1, \mathrm{CON}}$ ). Gray bars show ratios of steady-state EPSC amplitude (average of EPSCs $8-10$ of $200 \mathrm{~Hz}$ trains) in baclofen or $\mathrm{Cd}^{2+}$ relative to control ( $\mathrm{EPSC}_{\mathrm{SS} \text {, BAC (or Cd) }} / \mathrm{EPSC}_{\mathrm{SS}, \mathrm{CON}}$ ).

currents with $\mathrm{Cd}^{2+}$ could produce a similar enhancement of EPSC $_{\mathrm{SS}}$ (average of EPSCs 8-10). Bath application of $20 \mu \mathrm{M}$ $\mathrm{Cd}^{2+}$ reduced amplitudes of single EPSCs to $14 \pm 2 \%$ of controls, statistically indistinguishable from the effect of $50 \mu \mathrm{M}$ baclofen (Fig. 1B,D, black bars). Stimulus trains delivered at $200 \mathrm{~Hz}$ in the presence of $20 \mu \mathrm{M} \mathrm{Cd}^{2+}$ caused enhancement of EPSCs to $180 \pm 10 \%$ relative to control $(n=6)$ (Fig. $1 B-D$, gray bars). With equivalent levels of block of the first EPSC, the enhancement of EPSCs by $\mathrm{Cd}^{2+}$ and baclofen during $200 \mathrm{~Hz}$ trains was similar, suggesting that effects of baclofen result solely from a reduction of the initial probability of transmitter release (Kreitzer and Regehr, 2000). When trains of 30-50 stimuli were delivered ( $n=6$; data not shown), EPSC enhancement persisted under conditions of lowered $P_{\mathrm{R}}$, indicating that this enhancement is not a transient phenomenon attributable to a failure of EPSC amplitudes to reach steady-state.

\section{Synaptic strength is maximized at intermediate values of initial release probability}

To explore further the effect of changing initial $P_{\mathrm{R}}$ on $\mathrm{EPSC}_{\mathrm{SS}}$, we delivered $200 \mathrm{~Hz}$ stimulus trains while varying $P_{\mathrm{R}}$ with $\mathrm{Cd}^{2+}$. A high concentration of $\mathrm{Cd}^{2+}(100 \mu \mathrm{M})$, sufficient to block transmission in nMag completely, was applied by bath perfusion or local pressure ejection near the cell. $\mathrm{Cd}^{2+}$ levels were varied by gradual reperfusion of control bath solution (containing $0 \mu \mathrm{M}$
$\mathrm{Cd}^{2+}$ ) or by repositioning the puffer pipette various distances from the cell (Fig. 2Ai). Trains of EPSCs were recorded at $15 \mathrm{sec}$ intervals in concentrations of $\mathrm{Cd}^{2+}$ that ranged from 0 to $100 \mu \mathrm{M}$, producing a wide range of amplitudes of the first EPSC (EPSC $\left.{ }_{1}\right)$ in each train (Fig. 2Ai). Enhancement of $\mathrm{EPSC}_{\mathrm{SS}}$ was seen to accompany reduction of $P_{\mathrm{R}}$ (Fig. $\left.2 A i i\right)$. Figure $2 B$ illustrates the relationship between $\mathrm{EPSC}_{\mathrm{SS}}$ and $P_{\mathrm{R}}$. Figure 2, $A$ and $B$, shows an example in which maximal enhancement of $\mathrm{EPSC}_{\mathrm{SS}}$ was 411$422 \%$ when $\mathrm{EPSC}_{1}$ was reduced to between 7 and $12 \%$ of its control value. Further reductions of $P_{\mathrm{R}}$ caused EPSC $\mathrm{SS}_{\mathrm{SS}}$ to decline and approach zero, as expected with nearly complete block of $\mathrm{Ca}^{2+}$ channels. Similar observations were made in 11 neurons. Data were pooled from six neurons in which a large number of responses (25-135) were recorded (Fig. 2C). In this group, average enhancement of $\mathrm{EPSC}_{\mathrm{SS}}$ was $232 \%$ when $\mathrm{EPSC}_{1}$ was blocked with $\mathrm{Cd}^{2+}$ to between -1 and $-2 \mathrm{nA}$. These experiments demonstrate that $\mathrm{EPSC}_{\mathrm{SS}}$ amplitudes were enhanced under conditions of reduced $P_{\mathrm{R}}$.

Because modulation of $P_{\mathrm{R}}$ in vivo may occur via activation of presynaptic $\mathrm{GABA}_{\mathrm{B}}$ receptors, we used the same experimental approach to record EPSC trains in the presence of baclofen concentrations ranging from 0 to $100 \mu \mathrm{M}$ (Fig. 3). At $100 \mu \mathrm{M}$, the effect of baclofen is expected to be saturating, given an $\mathrm{IC}_{50}$ of 9 $\mu \mathrm{M}$ for baclofen of inhibition of the initial EPSC (data not 

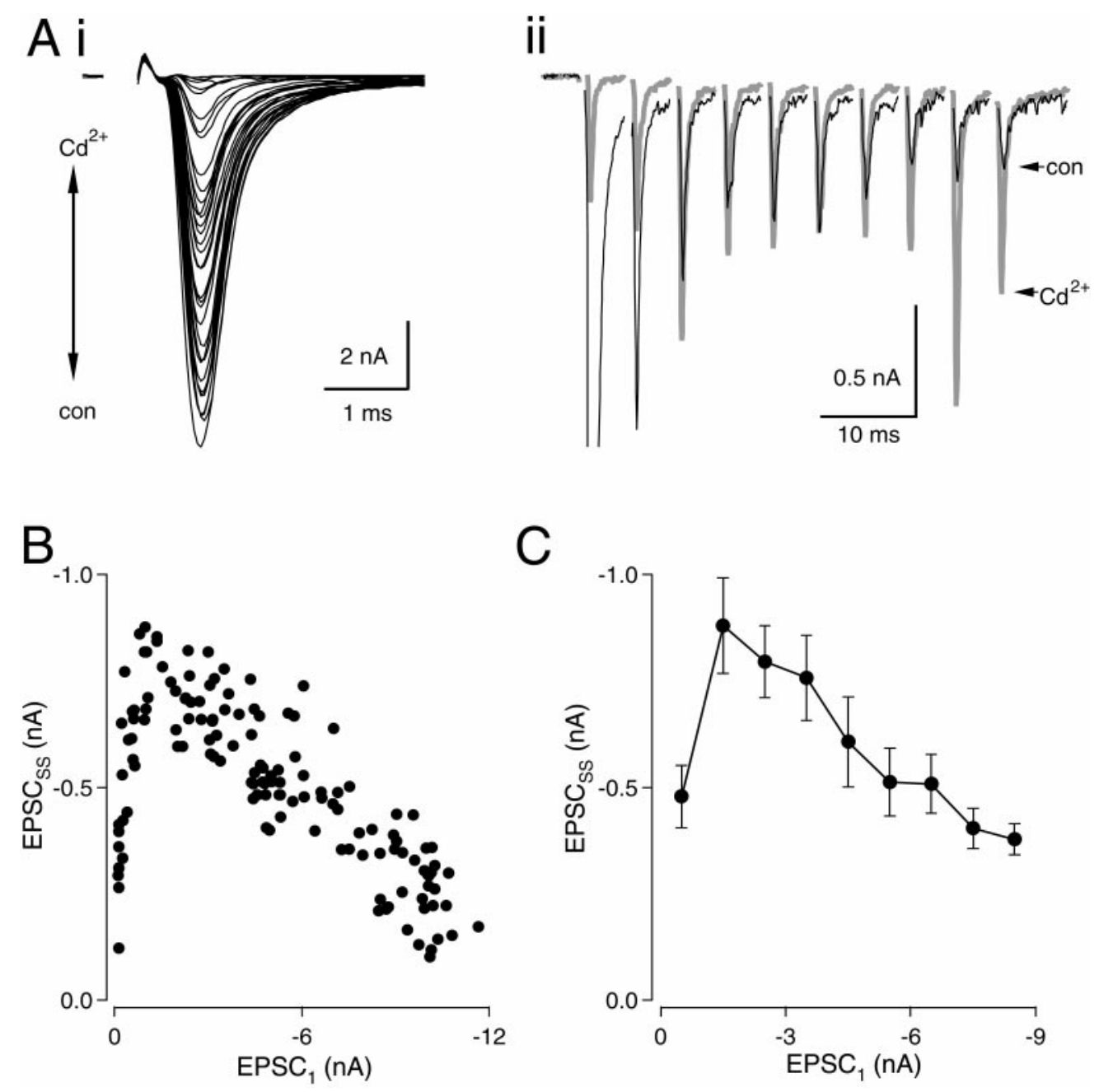

Figure 2. Relationship between EPSC $_{\mathrm{SS}}$ and $P_{\mathrm{R}}$. $A i$, Trains $(200 \mathrm{~Hz})$ of 10 stimuli were recorded in levels of $\mathrm{Cd}^{2+}$ ranging from 0 to $100 \mu \mathrm{M}$. The first EPSC in each train is shown. Aii, Superimposed traces in high $\mathrm{Cd}^{2+}$ (gray trace) and in $0 \mathrm{Cd}^{2+}$ (black trace). $B, \mathrm{EPSC}_{\mathrm{SS}}$ (averages of EPSCs $8-10)$ are plotted versus amplitude of the first EPSC for each train. $C$, Pooled results from six neurons. Data from each neuron were grouped in bins associated with EPSC $_{1}$ values from $0-1,1-2 \mathrm{nA}$, etc. Means and SEs were calculated for each bin. A linear fit to the data points (excluding the leftmost point associated with the smallest value of $\mathrm{EPSC}_{1}$ ) indicated a significant negative correlation between EPSC $_{1}$ and $\operatorname{EPSC}_{\mathrm{SS}}\left(r^{2}=0.968 ; p<0.0001\right)$.

shown). As noted earlier, baclofen enhanced EPSC $_{\mathrm{SS}}$ by more than twofold during $200 \mathrm{~Hz}$ trains, but unlike $\mathrm{Cd}^{2+}$, no suppression of $\mathrm{EPSC}_{\mathrm{SS}}$ was obtained even at the highest concentrations of baclofen. Figure $3, A$ and $B$, shows data from a neuron in which $\mathrm{EPSC}_{\mathrm{SS}}$ was enhanced 3.6-fold when the first EPSC in the train was reduced to $6.8 \%$ of its control value. As release during the first stimulus of the train was progressively blocked with saturating baclofen, the value of EPSC $_{\mathrm{SS}}$ increased and reached a plateau (Fig. 3B). Similar observations were made in 13 neurons. Data were pooled from six neurons in which numerous responses (43-96) were obtained (Fig. 3C). In this group, $\mathrm{EPSC}_{\mathrm{Ss}}$ was enhanced on average by $218 \%$ when EPSC $_{1}$ was reduced to less than $-3 \mathrm{nA}$ with baclofen. Thus, at high stimulus rates, full activation of $\mathrm{GABA}_{\mathrm{B}}$ receptors appears to maximize synaptic strength.

\section{Contribution of AMPA receptor desensitization to depression during high-frequency trains}

One hypothesis to account for the changes we observed in EPSC $_{\mathrm{SS}}$ that accompany changes in $P_{\mathrm{R}}$ is that AMPA receptors undergo desensitization during stimulus trains delivered only when $P_{\mathrm{R}}$ is high. To investigate the contribution of AMPA receptor desensitization to synaptic depression, we evoked trains of stimuli at $200 \mathrm{~Hz}$ in the presence of $5 \mathrm{~mm}$ aniracetam, a drug that reduces AMPA receptor desensitization (Vyklicky et al., 1991, Raman and Trussell, 1995b; Partin et al., 1996). Although desensitization will occur to high concentrations of glutamate in the presence of aniracetam, its onset is slowed dramatically in nMag, and should be minimal with stimulus intervals of $5 \mathrm{msec}$ (Raman and Trussell, 1995b; J. Lawrence and L. O. Trussell, unpublished observations). Effects of aniracetam on single EPSCs are shown in Fig. 4Ai. Control EPSC amplitudes were $-7.60 \pm 0.65$ versus $-10.52 \pm 0.97$ in $5 \mathrm{~mm}$ aniracetam (an increase of $37.2 \pm 4.3 \% ; n=16)$. Half-decay times were $0.80 \pm$ 0.04 for controls versus $2.33 \pm 0.12 \mathrm{msec}$ in aniracetam (an increase of $197 \pm 16 \% ; n=16$ ) (Fig. $4 \mathrm{Ai}$ ). Effects of aniracetam on peak amplitude and decay rate of AMPA-mediated EPSCs are attributed to modulation of receptor kinetics, which include an increase in the open time of the channel and a slowing of entry into desensitized states (Raman and Trussell, 1995b; Partin et al., 1996).

To determine the effect of aniracetam on synaptic depression during $200 \mathrm{~Hz}$ stimulation, we normalized peaks to the amplitude of the first EPSC in each train (Fig. 4Aii). By comparing relative amounts of depression after normalization, effects of aniracetam on desensitization during stimulus trains can be explored. Because EPSCs recorded at high frequency in aniracetam exhibited summation, peaks were measured from a baseline obtained by extrapolating the decay of the preceding EPSC using a singleexponential function. Synaptic depression during $200 \mathrm{~Hz}$ trains was reduced by aniracetam (Fig. 4Bi). After normalization of 

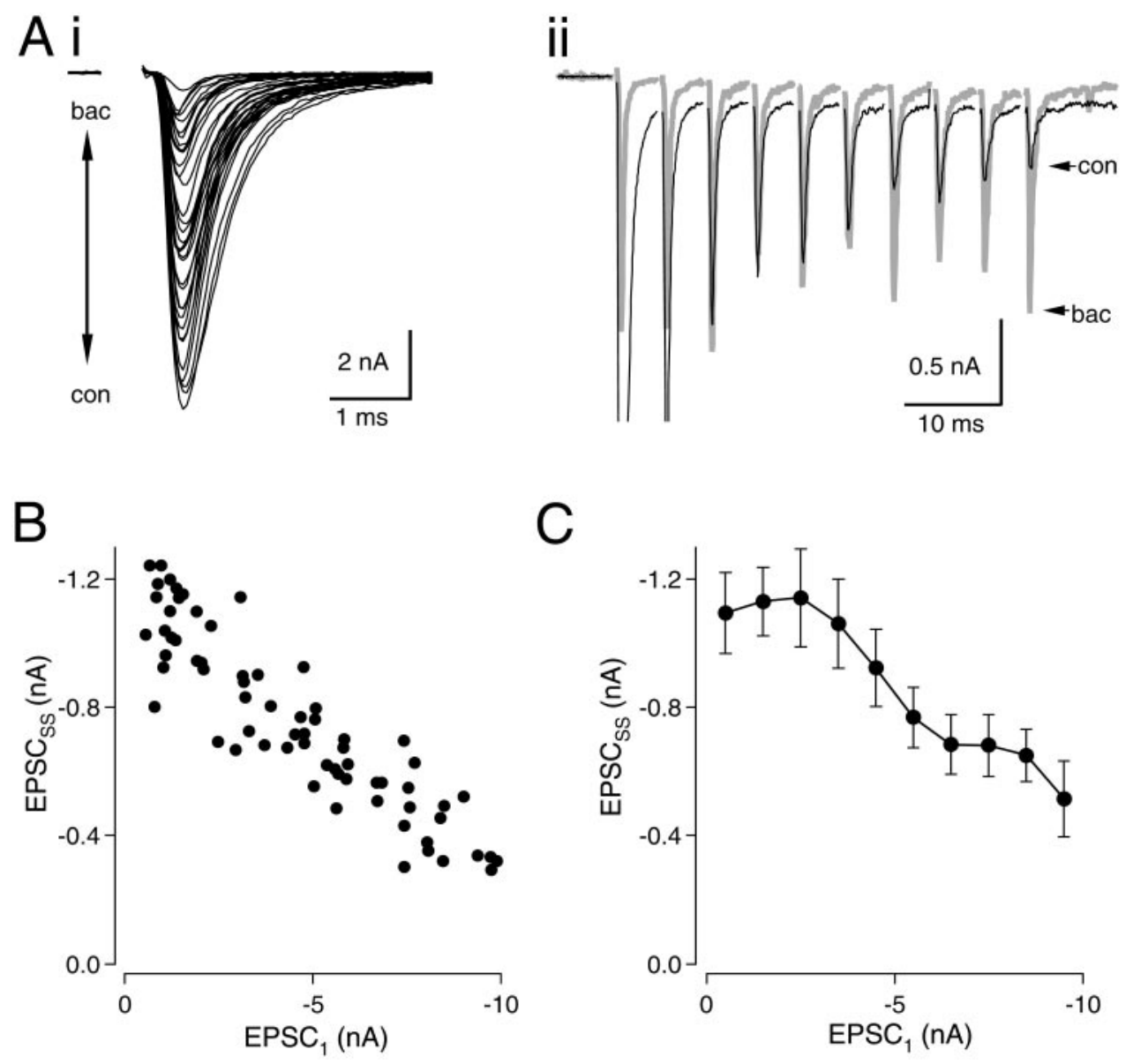

Figure 3. Effect of baclofen on EPSC $_{\text {Ss }}$. $A i$, Trains $(200 \mathrm{~Hz})$ were delivered in baclofen concentrations ranging from 0 to $100 \mu \mathrm{M}$. The first EPSC of the train is shown. Aii, Responses in 0 and $100 \mu \mathrm{M}$ baclofen are shown. After the second stimulus of the train, EPSCs in baclofen are larger than controls. $B$, EPSC $_{\mathrm{Ss}}$ is plotted against $\mathrm{EPSC}_{1}$ of each train. As $P_{\mathrm{R}}$ is lowered with baclofen, steady-state EPSCs increase in size, reaching a plateau as saturating levels of baclofen are reached. In this cell, enhancement of EPSC $_{\mathrm{SS}}$ relative to control was $361 \%$ when $\mathrm{EPSC}_{1}$ was reduced with baclofen to between 5.1 and $8.1 \%$ of its control value. $C$, Pooled data from six neurons. Data were binned as in Figure 2C. A linear fit to the eight rightmost data points was highly significant $\left(r^{2}=0.903 ; p<0.001\right)$.

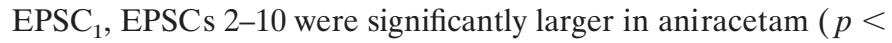
0.002 for each stimulus; paired $t$ test; $n=13$ ). Enhancement by aniracetam of EPSCs 2-10 of the train was calculated after normalization of $\mathrm{EPSC}_{1}$ as $100 \% \cdot\left(\mathrm{EPSC}_{\mathrm{ANI}}-\mathrm{EPSC}_{\mathrm{CON}}\right) /$ EPSC $_{\mathrm{CON}}$ (Fig. 4Bii). Maximal enhancement of the EPSC by aniracetam was seen during the second stimulus $(131 \%$ larger than control) and declined slightly during trains (110\% enhancement of the $10^{\text {th }}$ stimulus). Thus, over $50 \%$ of synaptic AMPA receptors remained desensitized throughout $200 \mathrm{~Hz}$ trains of 10 stimuli.

In contrast, when release was blocked by $\sim 85 \%$ with $20 \mu \mathrm{M}$ $\mathrm{Cd}^{2+}$ (Fig. 4Ci,Cii) or $50 \mu \mathrm{M}$ baclofen (data not shown), no effect of aniracetam on normalized EPSC amplitudes was observed (Fig. 4Cii). This suggests that desensitization contributes to synaptic depression under control release conditions but not when $P_{\mathrm{R}}$ is reduced by baclofen or $\mathrm{Cd}^{2+}$. Notably, the approximately twofold enhancement of EPSCs during $200 \mathrm{~Hz}$ trains by relief of desensitization (Fig. 4Bii) was similar to the enhancement of EPSCs observed when release was blocked with $\mathrm{Cd}^{2+}$ or baclofen (Figs. $1 D, 2 C, 3 B$ ). This similarity suggests that relief of desensitization may contribute to the enhancement of $\mathrm{EPSC}_{\mathrm{SS}}$ observed when $P_{\mathrm{R}}$ was lowered with $\mathrm{Cd}^{2+}$ or baclofen.

\section{Convergence of EPSC amplitudes with relief of desensitization}

Because desensitization caused a decrease in $\mathrm{EPSC}_{\mathrm{SS}}$ under highrelease conditions, we predicted that $\mathrm{EPSC}_{\mathrm{SS}}$ would remain constant over a wide range of initial release probabilities if desensitization was reduced by aniracetam. To test this hypothesis, experiments similar to those presented in Figure 2 were conducted in the continuous presence of $5 \mathrm{~mm}$ aniracetam. Trains were recorded at $15 \mathrm{sec}$ intervals while $P_{\mathrm{R}}$ was varied by bath application and subsequent washout of $100 \mu \mathrm{M} \mathrm{Cd}^{2+}$ (Fig. 5Ai). Under these conditions, EPSC $\mathrm{SS}_{\mathrm{S}}$ amplitudes converged on the same value during $200 \mathrm{~Hz}$ trains despite large changes in $P_{\mathrm{R}}$ (Fig. $5 A i i, B)$. Figure $5 B$ indicates that, whereas initial EPSC amplitudes varied fourfold (from -2 to $-8 \mathrm{nA}$ ), steady-state EPSCs remained constant at $\sim 1.5 \mathrm{nA}$. Similar results were obtained in eight neurons. Figure $5 C$ ( filled circles) shows pooled data from seven neurons from which a large number of responses (21-60) were recorded, as described in Figure 2. The slope of a linear regression of the eight rightmost data points in Figure 5C ( filled circles) was not significantly different from zero (slope of -0.029 ; $p=0.198)$. For comparison, the control data from Figure $2 C$ were scaled up by $37 \%$ to account for the effect of aniracetam on the initial EPSC amplitude and were plotted in Figure $5 C$ as open circles.

The experiments presented in Figure 5 demonstrate that, in the presence of aniracetam, EPSCs approach the same amplitude during trains despite large variations in the transmitter release probability, in agreement with predictions of purely presynaptic depletion models of synaptic depression (see below). These data indicate that the progressive decline in $\mathrm{EPSC}_{\mathrm{SS}}$ seen as $P_{\mathrm{R}}$ increased (Figs. $2 C, 3 B$ ) results from AMPA receptor desensitization under high-release conditions. Thus, relief of desensitization can account for the enhancement of EPSC $_{\mathrm{SS}}$ that results from lowering $P_{\mathrm{R}}$ by $\mathrm{GABA}_{\mathrm{B}}$ receptor activation or $\mathrm{Cd}^{2+}$ application. 

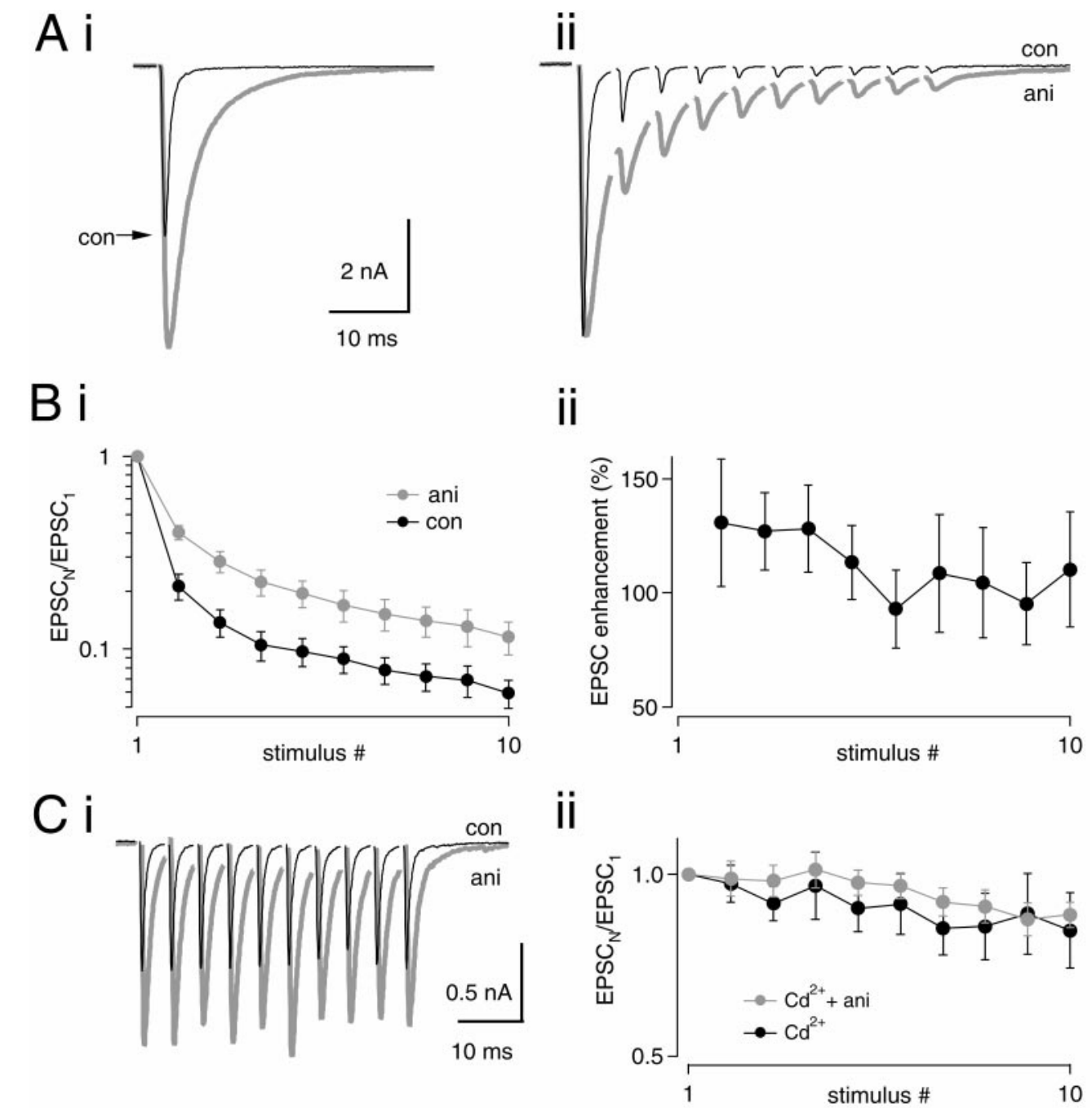

Figure 4. Effect of aniracetam on synaptic depression. Ai, A single EPSC in 5 mm aniracetam (gray trace). Control peak (black trace) is indicated with an arrow. In this cell, aniracetam increased the peak amplitude by $60 \%$ (from -6.19 to $-10.24 \mathrm{nA}$ ). Aii, A $200 \mathrm{~Hz}$ train in control (black trace) and aniracetam (gray trace) is shown. Traces have been normalized to the amplitude of the first peak in each train. Averages of five traces are shown. Bi, Normalized peak amplitudes during $200 \mathrm{~Hz}$ stimulus trains (control, black circles; aniracetam, gray circles). Data from 13 cells. Depression is significantly reduced by aniracetam for stimuli $2-10$ of trains ( $p<0.01$; paired $t$ test). Bii, Relative enhancement of EPSC amplitudes by aniracetam throughout the train, calculated as $100 \% \cdot\left(\mathrm{EPSC}_{\mathrm{ANI}}-\mathrm{EPSC}_{\mathrm{CON}}\right) / \mathrm{EPSC}_{\mathrm{CON} \cdot} C$, Effect of aniracetam on synaptic depression in the continuous presence of $20 \mu \mathrm{M} C \mathrm{~d}^{2+}$. $\mathrm{Ci}$, EPSC trains at $200 \mathrm{~Hz}$ in $20 \mu \mathrm{M} \mathrm{Cd}^{2+}$ (black trace) and $20 \mu \mathrm{M} \mathrm{Cd}^{2+}$ plus $5 \mathrm{~mm}$ aniracetam (gray trace). In this example, aniracetam increased the peak of the first EPSC by $55.8 \%$ (from 0.84 to $1.30 \mathrm{nA}$ ). Cii, Responses during trains in the presence of $\mathrm{Cd}^{2+}$ (black circles) and Cd ${ }^{2+}$ plus aniracetam ( gray circles) were normalized to the first response amplitude and plotted versus stimulus number. No effect of aniracetam on synaptic depression was seen when $P_{\mathrm{R}}$ was lowered with $20 \mu \mathrm{M} \mathrm{Cd}^{2+}(n=12)$.

\section{Alternative actions of aniracetam}

Control experiments were performed to determine whether presynaptic effects of aniracetam might have influenced the above conclusions, although previous studies found no effect of aniracetam on quantal content of EPSCs (Vyklicky et al., 1991). Effects of aniracetam on transmitter release were expected to alter paired-pulse ratios $\left(\mathrm{EPSC}_{2} / \mathrm{EPSC}_{1}\right)$ of $\mathrm{NMDA}$ responses, as reported previously for cyclothiazide (Bellingham and Walmsley, 1999). NMDA-mediated EPSCs were recorded at $+50 \mathrm{mV}$ in the presence of AMPA receptor blockers. Paired stimuli were delivered at $20 \mathrm{msec}$ intervals under control conditions (Fig. 6 $\mathrm{Ai}$ ) or in the presence of $5 \mathrm{~mm}$ aniracetam (Fig. 6Aii). Paired-pulse ratios for the NMDA component of the EPSC were compared in nine neurons (Fig. 6B). For controls, average paired-pulse ratio was $0.27 \pm 0.01$; in the presence of $5 \mathrm{~mm}$ aniracetam, the average value was $0.26 \pm 0.01$. These values were not significantly differ- ent ( $p=0.480$; paired $t$ test). Paired-pulse ratios of AMPAmediated EPSCs were significantly larger (paired-pulse ratio of $0.49 \pm 0.02 ; p<0.01$; paired $t$ test) (Fig. $6 C$ ). Based on the higher affinity of the NMDA receptor for glutamate, we attribute this finding to greater occupancy of NMDA receptors at the onset of the second stimulus. Receptor desensitization may also contribute to paired-pulse depression (PPD) of NMDA responses. Additional evidence for a purely postsynaptic site of action for aniracetam is indicated by the absence of an effect of aniracetam on the relative amplitudes of AMPA-mediated EPSCs during stimulus trains under low $P_{\mathrm{R}}$ conditions (Fig. 4Cii).

As transmitter release declines during high-frequency trains, it is possible that postsynaptic sites are exposed to progressively lower concentrations of glutamate. If this were true, then EPSC enhancement by aniracetam during trains might simply be an outcome of the drug increasing the affinity of AMPA receptors, 

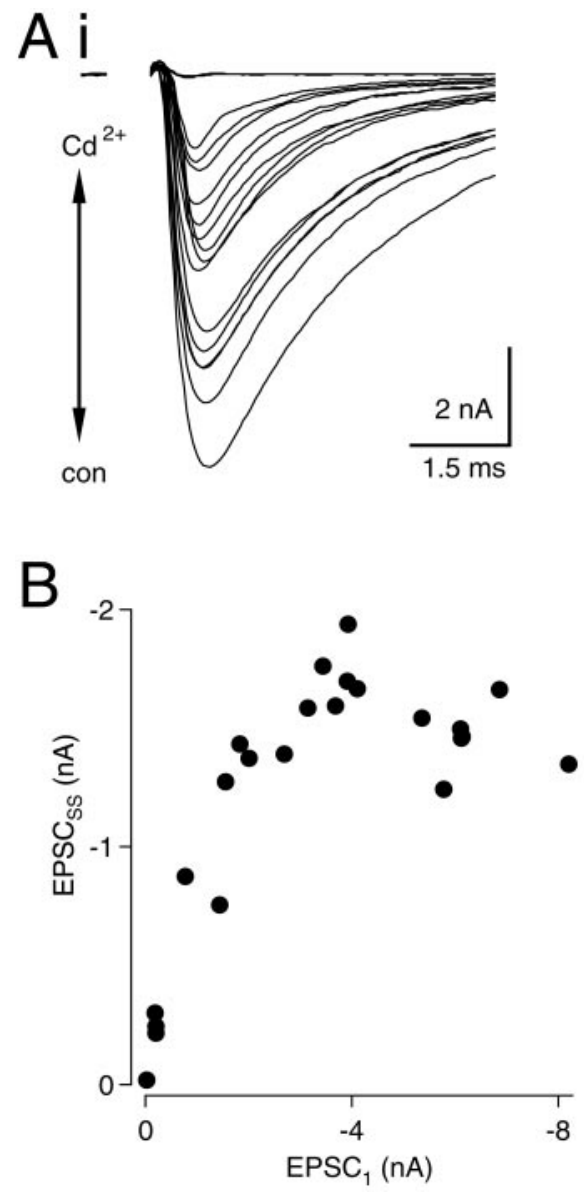
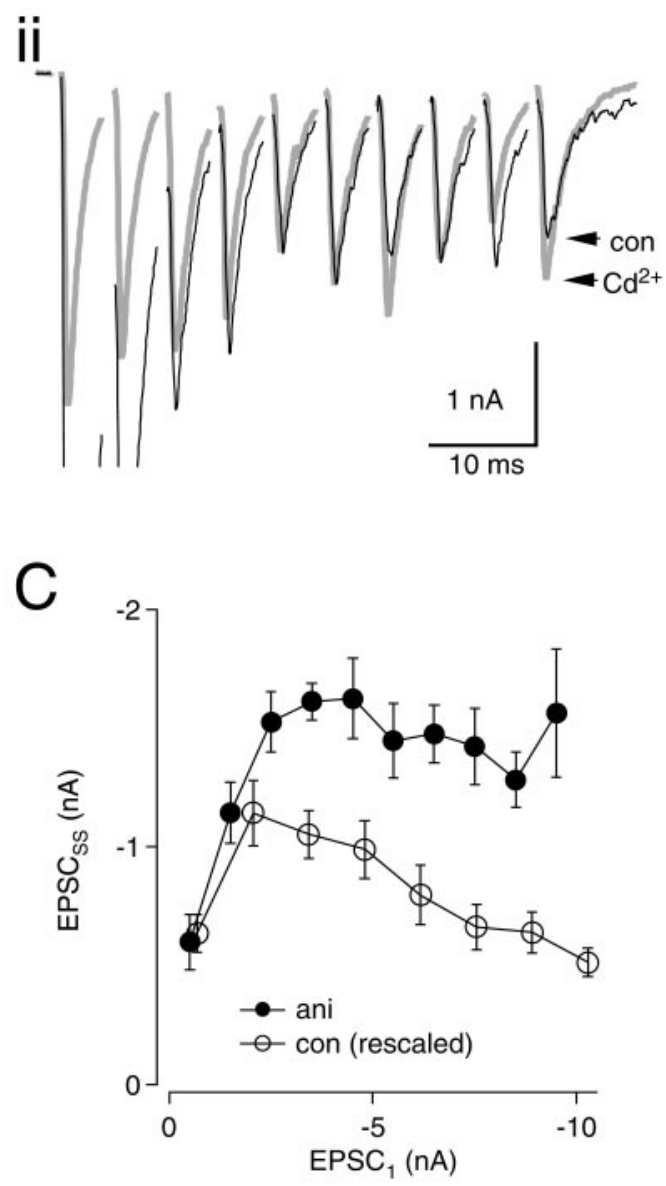

Figure 5. Convergence of $\mathrm{EPSC}_{\mathrm{SS}}$ in the presence of aniracetam $A$, In the continuous presence of $5 \mathrm{~mm}$ aniracetam, 200 $\mathrm{Hz}$ trains of 10 stimuli were delivered in various concentrations of $\mathrm{Cd}^{2+}$ ranging from 0 to $100 \mu \mathrm{M}$. $A i$, The first EPSC of each train is shown. Aii, Superimposed traces in high $\mathrm{Cd}^{2+}$ (gray trace) and low $\mathrm{Cd}^{2+}$ (black trace) are shown. B, EPSC $\mathrm{SS}$ is plotted versus EPSC $_{1}$ for each train. $C$, Data from seven cells in aniracetam ( filled circles). As in Figure 2, data from each neuron were grouped in bins associated with EPSC $_{1}$ values from $0-1,1-2 \mathrm{nA}$, etc. Means and SEs were calculated for each bin. The slope of a linear fit to the data points (excluding the 2 leftmost points associated with $\mathrm{EPSC}_{1}$ values from 0 to 2 $\mathrm{nA}$ ) was not significantly different from 0 $\left(r^{2}=0.26 ; p=0.20\right)$. Control data from Figure $2 C$ have been scaled up by a factor of 1.37 to account for the effect of aniracetam on the amplitude of a single EPSC (see Fig. 4A) and are shown for comparison (open circles).
A i.

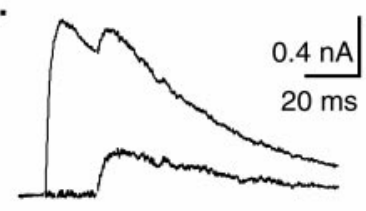

ii.

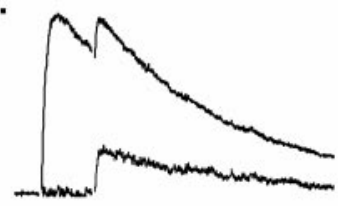

B.

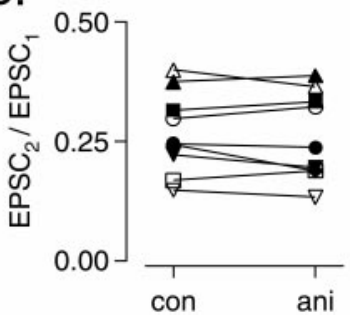

C.

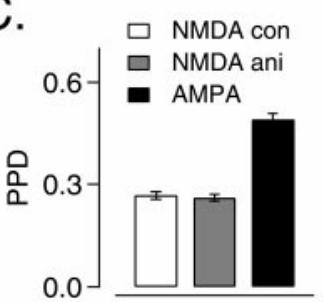

Figure 6. NMDA component of EPSC is not affected by aniracetam. $A$, Pairs of EPSCs at $20 \mathrm{msec}$ intervals were recorded at $+50 \mathrm{mV}$ in GYKI-52466 and DNQX under control conditions $(A i)$ and in $5 \mathrm{~mm}$ aniracetam (Aii). Average of five traces. Peak 2 (bottom traces) in $A i$ and Aii was obtained by subtraction of the averaged single EPSC (data not shown). $B$, Paired-pulse ratios (EPSC $2 / \mathrm{EPSC}_{1}$ ) for responses in control solutions and in $5 \mathrm{~mm}$ aniracetam $(n=9)$. $C$, Average values of $\mathrm{EPSC}_{2} /$ $\mathrm{EPSC}_{1}$ for NMDA component of EPSC (control and aniracetam) and AMPA component (control; $n=9$ ).

apart from preventing desensitization. We determined whether the effectiveness of aniracetam changed with quantal content by comparing the effects of the drug on mEPSCs and evoked EPSCs.

If receptors were farther from saturation during mEPSCs than during EPSCs, then the effects of aniracetam on peak current should be greatest for mEPSCs. However, this was not the case. In a group of six neurons, mEPSCs enhancement by aniracetam was $14.5 \pm 5.2 \%$, slightly less than enhancement of evoked EPSCs, which was $25.7 \pm 6.9 \%$. These values were not significantly different ( $p=0.12$; paired $t$ test). Thus, effects of aniracetam on affinity of AMPA receptors for glutamate cannot account for the enhancement of EPSC amplitudes during trains.

\section{Quantal amplitudes are depressed after single stimuli and after trains}

It has been shown previously in nMag that desensitization of AMPA receptors causes a decrease in the size of the mEPSC immediately after a single evoked EPSC (Otis et al., 1996b). Others, however, have not observed a decrease in postsynaptic responsiveness to transmitter after a single EPSC (Silver et al., 1998; Bellingham and Walmsley, 1999) or during trains (Silver et al., 1998). We therefore reexamined this effect, in particular contrasting changes in quantal size with single or multiple conditioning EPSCs. After EPSCs evoked in the presence of $\mathrm{Sr}^{2+}$ (2-4 mM), an elevated frequency of asynchronous quantal release is observed in nMag (Otis et al., 1996b) and other preparations (Rahamimoff and Yaari, 1973; Xu-Friedman and Regehr, 1999). Therefore, we recorded single EPSCs and trains of five EPSCs at $200 \mathrm{~Hz}$, in the presence of $\mathrm{Sr}^{2+}$. Amplitude and latency of quantal events were measured after the stimulus (Fig. 7Ai,Bi). Between 50 and 100 consecutive traces were recorded to obtain sufficient quantal events for analysis (Fig. 7Aii,Bii). Quantal amplitudes were sorted by latency and binned into groups of 30 
Figure 7. Depression of quantal size during stimulus trains. $A i$, Averaged EPSC recorded in $3 \mathrm{mM} \mathrm{Sr}^{2+}$. Aii, Twenty superimposed traces after a single stimulus. Asynchronously released quanta are visible arising from the decay of the preceding EPSC. Dotted line indicates zerocurrent baseline. Aiii, Means and SE of amplitude and latency for quantal events binned in groups of 30 . For this synapse, the amplitude of the first bin was depressed by $49 \%$ relative to the steady-state amplitude at longer latencies. A singleexponential fit to the data gave a recovery time course of $27 \mathrm{msec}$. Bi, Averaged traces from a train of five stimuli at 200 $\mathrm{Hz}$ in $3 \mathrm{~mm} \mathrm{Sr}^{2+}$. Bii, Twenty-five superimposed traces after the fifth EPSC of the train shown in Bi. Biii, Mean amplitude and latency for quantal events binned in groups of 30. In this synapse, the amplitude of the first bin was depressed by $38 \%$ relative to steady-state amplitude at longer latencies. Recovery time course of quantal amplitudes was $11 \mathrm{msec}$.
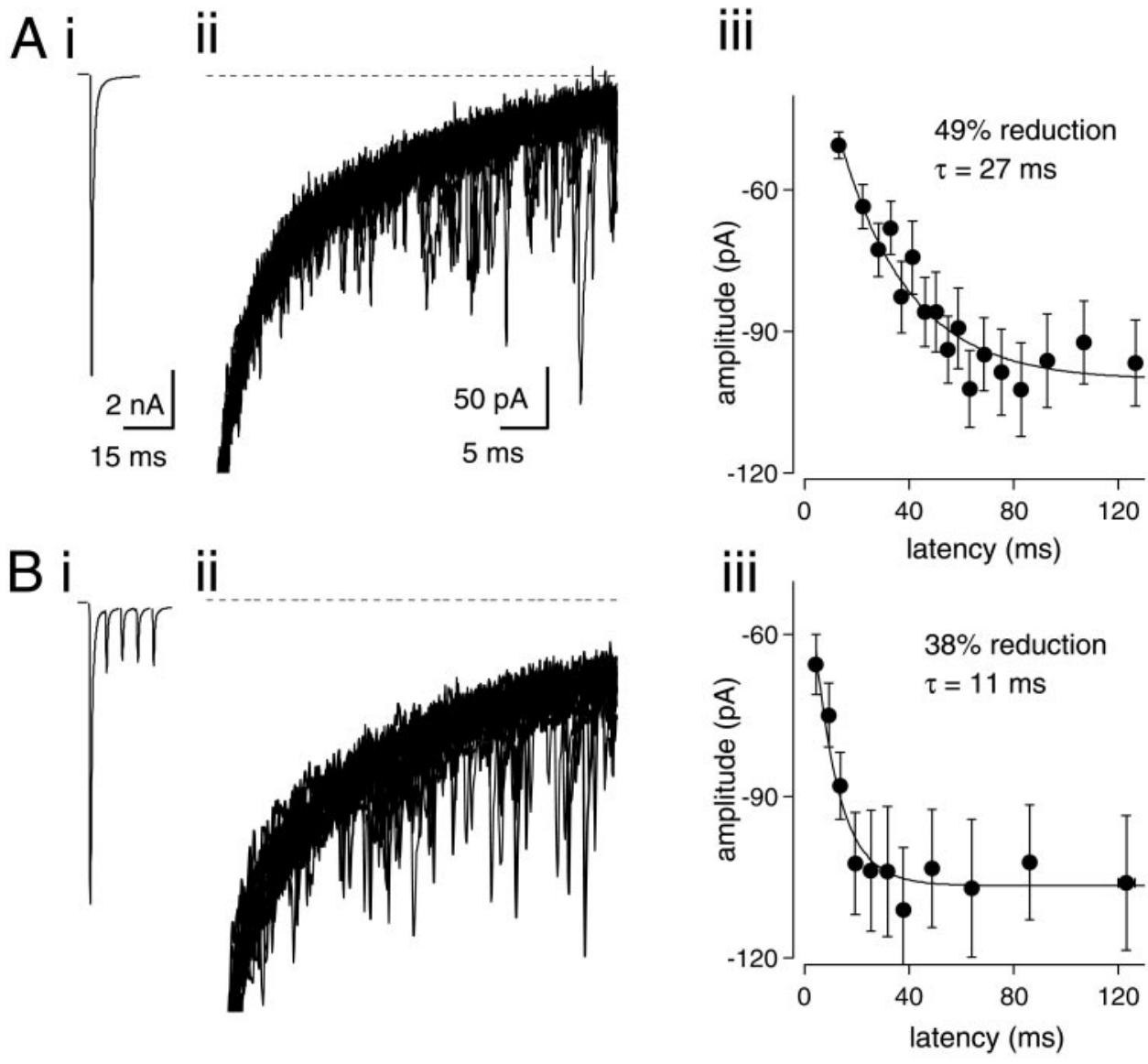

successive events. For each bin, mean amplitude was plotted against mean latency from the peak of the preceding EPSC (Fig. 7Aiii,Biii). After one and five stimuli, quantal amplitudes were depressed by $36.5 \pm 3.9(n=5)$ and $36.3 \pm 3.5 \%(n=5)$, respectively. Amplitudes recovered with a single-exponential time constant of $21.1 \pm 2.9$ and $10.6 \pm 2.0 \mathrm{msec}$, respectively. The overall extent of depression after one or five stimuli was not statistically different; however, the time course of recovery was significantly faster after five stimuli ( $p<0.01 ; t$ test). In these experiments, a maximum train length of five stimuli was used because longer trains resulted in a high frequency of asynchronous quantal release whose superposition prevented resolution of individual events. These results are in agreement with the results obtained using aniracetam (Fig. 4), indicating the persistent desensitization of AMPA receptors during high-frequency stimulus trains.

\section{Modeling depression and desensitization}

Simulations were performed to determine whether the experimental results presented in Figures 2 and 5 could be explained by incorporating receptor desensitization into a depletion model of synaptic depression (Fig. 8). The model consists of a synapse with $N_{0}$ release sites that release transmitter with probability $P_{\mathrm{R}}$ after a presynaptic action potential. Sites becomes refractory immediately after release and subsequently recover with a singleexponential time course (see Materials and Methods). Although alternative presynaptic models have been developed (Wu and Borst, 1999; Kraushaar and Jonas, 2000; Matveev and Wang, 2000), a depletion model was used here because it accurately reproduced our synaptic data obtained in the presence of anirac- etam. Postsynaptic desensitization was modeled by introducing a scaling factor in the model that reduced quantal size uniformly at all sites and was dependent on the amount of release. Desensitization had an exponential relationship to the amount of release and recovered with a single-exponential time course. Parameters of the model were determined by fitting the simulated results to the data shown in Figure $4 B$. The presynaptic component of the model is similar in many respects to previously published models (O’Donovan and Rinzel, 1997, Dittman and Regehr, 1998, Weis et al., 1999; Lu and Trussell, 2000).

Figure $8 A$ shows results of simulations of $200 \mathrm{~Hz}$ stimulus trains using a presynaptic depletion model in which $P_{\mathrm{R}}$ ranged from 0.02 to 0.75 . At steady state, each presynaptic action potential evoked release from $\sim 8 \%$ of the total population of release sites when initial release probability is greater than 0.15 (Fig. $8 A, C)$. As $P_{\mathrm{R}}$ decreased below 0.15 , the amount of release was no longer limited by interstimulus recovery but instead was limited by extremely low fusion probability. As shown in Figure $8 C$ ( filled circles), a purely presynaptic model of depression predicted that steady-state EPSC amplitudes evoked at high frequency (i.e., the stimulus interval is much faster than the time constant of recovery from depression) converge on the same value despite large changes in initial release probability. However, when the model incorporated postsynaptic receptor desensitization (see Materials and Methods), we observed a progressive reduction of $\mathrm{EPSC}_{\mathrm{SS}}$ as $P_{\mathrm{R}}$ increased (Fig. 8B,C, open circles), in agreement with our experimental results (Figs. $2 B, C, 3,5 C$ ). The ability of this model to reproduce these key features of our experimental results strongly suggests that desensitization can account for the decline in $\mathrm{EPSC}_{\mathrm{SS}}$ with high $P_{\mathrm{R}}$. 
A
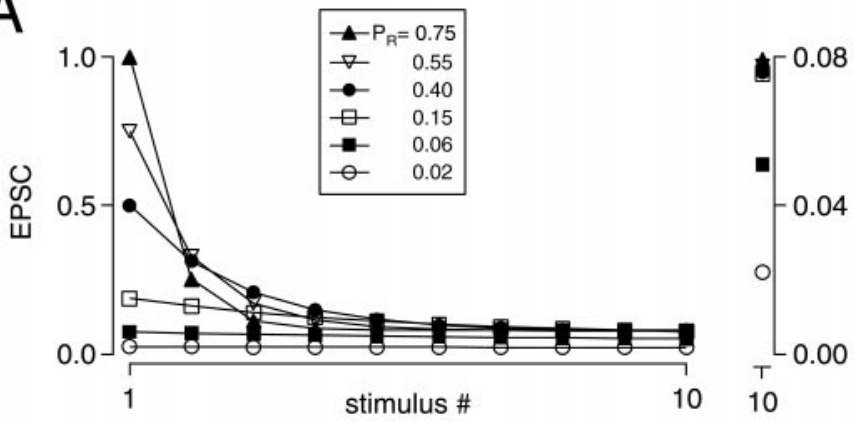

B
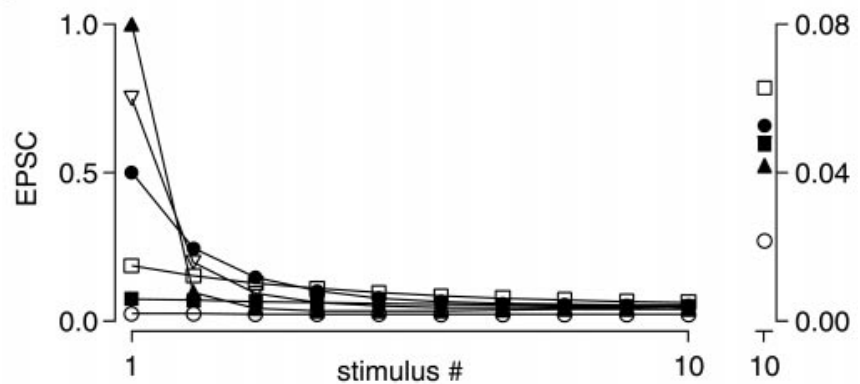

C

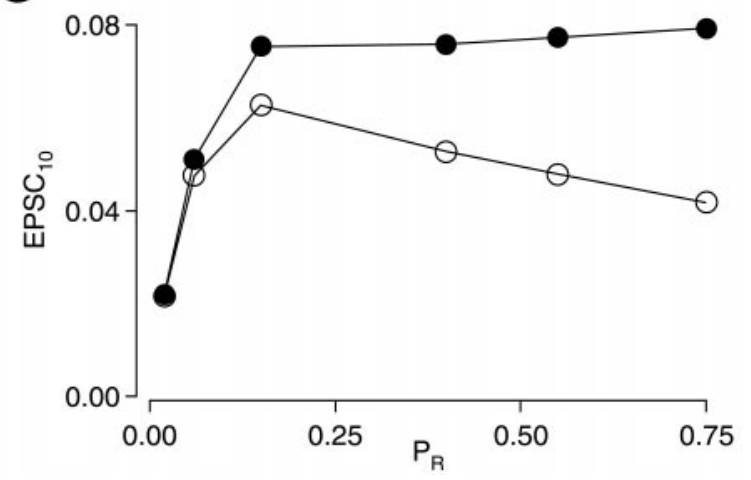

Figure 8. Depletion and desensitization model of synaptic depression. $A$, Simulations based on a presynaptic depletion model that does not include receptor desensitization. Trains of 10 stimuli at $200 \mathrm{~Hz}$ with $P_{\mathrm{R}}$ values ranging from 0.02 to 0.75 . Smaller responses to stimulus \#1 correspond to lower $P_{\mathrm{R}}$ values. Time constant of recovery from depression was $100 \mathrm{msec}$. EPSCs reached similar steady-state values when $P_{\mathrm{R}}$ ranged from 0.15 to 0.75 . Inset on right shows the 10th response on an expanded vertical scale. Note that data points are superimposed from trains with $P_{\mathrm{R}}$ of 0.15 to 0.75 . $Y$ values (normalized to $\mathrm{EPSC}_{1}$ ) for these four data points ranged from 0.075 to 0.079 . B , Desensitization was included in the model as described in Materials and Methods. $P_{\mathrm{R}}$ was varied as in $A$. Steady-state EPSCs were maximal at $P_{\mathrm{R}}=0.15$. Inset shows 10 th response on an expanded vertical scale. $C$, EPSC $\mathrm{SS}_{\mathrm{SS}}$ is plotted versus $\mathrm{EPSC}_{1}$. Results of the presynaptic model are shown by filled circles; results of simulations incorporating postsynaptic desensitization are shown with open circles.

\section{DISCUSSION}

This work demonstrates that desensitization of AMPA receptors contributes strongly to synaptic depression during high-frequency activity at avian end-bulb synapses in the auditory brainstem. Desensitization was dependent on the amount of transmitter release at the onset of a stimulus train. With high initial transmitter release probability, approximately half of the postsynaptic AMPA receptors were desensitized at the end of a $50 \mathrm{msec}, 200$
$\mathrm{Hz}$ stimulus train. However, desensitization decreased as $P_{\mathrm{R}}$ was reduced, thereby enhancing amplitudes of steady-state EPSCs during stimulus trains. Thus, relief of AMPA receptor desensitization can account for the enhancement of steady-state EPSC amplitudes that accompany reduction of release probability with baclofen or $\mathrm{Cd}^{2+}$.

During stimulus trains, transmitter release approaches a steady-state that occurs when vesicle depletion after each stimulus is equal to recovery between stimuli. Depression models that consider only transmitter depletion predict that, during highfrequency stimulation, the steady-state EPSC amplitude is independent of $P_{\mathrm{R}}$ (except for extremely low $P_{\mathrm{R}}$ ) because of an inverse relationship between $P_{\mathrm{R}}$ and the size of the steady-state vesicle pool. With high $P_{\mathrm{R}}$, steady-state pool size is small and a large fraction of the pool is released with each stimulus, but with low $P_{\mathrm{R}}$, the steady-state pool size is large and only a small proportion of available release sites undergo exocytosis with each stimulus. This ideal relationship is an approximation that holds at stimulus frequencies for which the interval between stimuli is much shorter than the time constant of recovery from depression. In our experiments, block of desensitization resulted in convergence of EPSC amplitudes during high-frequency trains, indicating that release approaches a steady-state during the stimulus trains. If $\mathrm{Ca}^{2+}$-dependent processes cause acceleration of recovery from synaptic depression, as described at other synapses (Dittman and Regehr, 1998; Stevens and Wesseling, 1998; Wang and Kaczmarek, 1998; Wang and Zucker, 1998) (but see Weis et

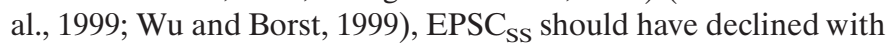
reductions in presynaptic $\mathrm{Ca}^{2+}$ influx, i.e., as $\mathrm{EPSC}_{1}$ was lowered. However, $\mathrm{EPSC}_{\mathrm{SS}}$ was independent of $\mathrm{EPSC}_{1}$ over a wide range of release probabilities after block of postsynaptic depression. This suggests that, over the range of $\mathrm{Ca}^{2+}$ influx associated with this range of release probabilities, $\mathrm{Ca}^{2+}$-dependent processes act at a constant level, and perhaps under our experimental conditions $\mathrm{Ca}^{2+}$-dependent recovery processes are saturated by $\mathrm{Ca}^{2+}$ influx during trains of stimuli.

Changes in release probability have presynaptic and postsynaptic effects on transmission at the end-bulb synapse. Under low-release conditions, release of relatively few vesicles results in a rapidly decaying glutamate transient at a receptor cluster opposite an active release site. With higher release probability, transmitter will be released synchronously from many sites, generating a slower phase of decay of the glutamate transient in the synaptic cleft (Otis et al., 1996a). We observed a current plateau between EPSCs during $200 \mathrm{~Hz}$ trains, which has been attributed to accumulation of glutamate in the synaptic cleft (Turecek and Trussell, 2000). Modeling studies have suggested that the glutamate concentration in the synaptic cleft will remain above $10 \mu \mathrm{M}$ for tens of milliseconds after release under high $P_{\mathrm{R}}$ conditions. AMPA receptors undergo desensitization in the presence of micromolar concentrations of agonist insufficient to cause channel openings (Raman and Trussell, 1992). Experiments in which glutamate was applied to membrane patches excised from nMag neurons indicate that $10 \mu \mathrm{m}$ glutamate will induce $\sim 70 \%$ steadystate desensitization of AMPA receptors (Raman and Trussell, 1992). Thus, low concentrations of glutamate that persist in the synaptic cleft during trains may contribute to desensitization that we observed during periods of high-frequency synaptic activation.

In addition, brief exposure of AMPA receptors to high concentrations of agonists can induce a form of desensitization that accompanies channel opening. One millisecond application of 1 mM glutamate to membrane patches at room temperature caused 
$50 \%$ desensitization of AMPA receptors, which subsequently recovered with a $16 \mathrm{msec}$ exponential time constant (Raman and Trussell, 1995a). During trains, the relative contribution to desensitization of prolonged exposure to low glutamate concentrations and brief exposure to high concentrations is not known.

At room temperature, a single evoked EPSC desensitized 35$40 \%$ of synaptic AMPA receptors, recovering with a time constant of 68 msec (Otis et al., 1996b). At near-physiological temperatures, we observed a greater extent of desensitization, which recovered with a time constant of $21 \mathrm{msec}$. Faster recovery may be attributable to more rapid clearance of glutamate from the synaptic cleft and faster gating kinetics of AMPA receptors. Desensitization of AMPA receptors during synaptic activation was also shown to be dependent on the total amount of transmitter release (Trussell et al., 1993). PPD of EPSCs in low $\mathrm{Ca}^{2+}$ showed little sensitivity to cyclothiazide, but in higher $\mathrm{Ca}^{2+}$ concentrations, relief of PPD by cyclothiazide was observed. Moreover, synaptic depression during $200 \mathrm{~Hz}$ trains was reduced by cyclothiazide (Zhang and Trussell, 1994a) and by a glutamate scavenging enzyme (Turecek and Trussell, 2000), indicating persistent AMPA receptor desensitization during periods of repetitive stimulation. These results are consistent with our observation that desensitization persists during stimulus trains delivered under conditions of high $P_{\mathrm{R}}$ but not under conditions of low $P_{\mathrm{R}}$.

Because we demonstrate that desensitization depends on the amount of evoked release during trains, it is predicted that presynaptic depression will allow receptors to recover from desensitization during periods of prolonged activity. During $200 \mathrm{~Hz}$ stimulation, $<10 \%$ of release sites undergo exocytosis after each stimulus so that, on average, several stimuli will elapse between successive events of vesicle fusion at a particular release site. However, we saw little decline in the extent of receptor desensitization during $50 \mathrm{msec}$ trains (Fig. 4Bii), as estimated by the enhancing effect of aniracetam. The persistence of AMPA receptor desensitization despite $>90 \%$ reduction in transmitter release may be explained by accumulation and slow clearance of transmitter in the synaptic cleft.

Although a large reduction of $P_{\mathrm{R}}$ by $\mathrm{Cd}^{2+}$ ultimately caused a decline in $\mathrm{EPSC}_{\mathrm{SS}}$ from its plateau value (Fig. $2 C$ ), reduction of $P_{\mathrm{R}}$ by $\mathrm{GABA}_{\mathrm{B}}$ receptor activation using a saturating concentration of agonist always raised $\mathrm{EPSC}_{\mathrm{SS}}$. Based on a 3 rd or 4 th power relationship between calcium influx and transmitter release (Dodge and Rahamimoff, 1967; Augustine and Charlton, 1986; Borst and Sakmann, 1996), an $85 \%$ reduction of a single EPSC by saturating levels of baclofen indicates that maximal activation of $\mathrm{GABA}_{\mathrm{B}}$ receptors reduced presynaptic calcium influx by 38$47 \%$. This observation suggests precise regulation of the coupling between $\mathrm{GABA}_{\mathrm{B}}$ receptors and $\mathrm{Ca}^{2+}$ channels involved in transmitter release, so that release is never actually inhibited during intense activity. Sites of such regulation could include the number of $\mathrm{GABA}_{\mathrm{B}}$ receptors, levels of expression of G-proteins, extent of modulation of particular $\mathrm{Ca}^{2+}$ channels subtypes, and the degree of coupling of different $\mathrm{Ca}^{2+}$ channel types to release.

Synaptic depression has been proposed to play an important role in promoting network stability in the cerebral cortex (Galarreta and Hestrin, 1998) and has been described as a mechanism that enables neurons to maintain responsiveness to the firing patterns of a large number of afferents (Abbott et al., 1997). However, at end-bulb synapses in the cochlear nucleus, a role for synaptic depression is less clear. Bushy cells serve as relays in a timing pathway enabling sound localization (Carr and Konishi, 1990; Overholt et al., 1992). In the avian brainstem, GABAergic neurons from the superior olivary nucleus are activated by sounds and project to nMag, in which they may activate $\mathrm{GABA}_{\mathrm{B}}$ receptors on auditory nerve terminals (Lachica et al., 1994; Monsivais et al., 2000). The feed-forward nature of this pathway should cause GABA release by superior olivary neurons to increase approximately in parallel with end-bulb synaptic activity. Because desensitization is likely to result from in vivo firing rates of the auditory nerve, activation of presynaptic $\mathrm{GABA}_{\mathrm{B}}$ receptors could serve to minimize synaptic depression by relieving desensitization, thereby allowing suprathreshold transmission to persist at higher rates of synaptic activity. Such an enhancement of gain may help widen the dynamic range of sensory signaling.

\section{REFERENCES}

Abbott LF, Varela JA, Sen K, Nelson SB (1997) Synaptic depression and cortical gain control. Science 275:220-224.

Augustine GJ, Charlton MP (1986) Calcium dependence of presynaptic calcium current and post-synaptic response at the squid giant synapse. J Physiol (Lond) 381:619-640.

Bean BP (1989) Neurotransmitter inhibition of neuronal calcium currents by changes in channel voltage dependence. Nature 340:153-156.

Bellingham MC, Walmsley B (1999) A novel presynaptic inhibitory mechanism underlies paired pulse depression at a fast central synapse. Neuron 23:159-170.

Betz WJ (1970) Depression of transmitter release at the neuromuscular junction of the frog. J Physiol (Lond) 206:629-644.

Borst JG, Sakmann B (1996) Calcium influx and transmitter release in a fast CNS synapse. Nature 383:431-434.

Brenowitz S, David J, Trussell L (1998) Enhancement of synaptic efficacy by presynaptic GABA(B) receptors. Neuron 20:135-141.

Carr CE, Konishi M (1990) A circuit for detection of interaural time differences in the brain stem of the barn owl. J Neurosci 10:3227-3246.

DelCastillo J, Katz B (1954) Statistical factors involved in neuromuscular facilitation and depression. J Physiol (Lond) 124:574-585.

Dittman JS, Regehr WG (1996) Contributions of calcium-dependent and calcium-independent mechanisms to presynaptic inhibition at a cerebellar synapse. J Neurosci 16:1623-1633.

Dittman JS, Regehr WG (1998) Calcium dependence and recovery kinetics of presynaptic depression at the climbing fiber to Purkinje cell synapse. J Neurosci 18:6147-6162.

Dobrunz LE, Stevens CF (1997) Heterogeneity of release probability, facilitation, and depletion at central synapses. Neuron 18:995-1008.

Dodge Jr FA, Rahamimoff R (1967) Co-operative action a calcium ions in transmitter release at the neuromuscular junction. J Physiol (Lond) 193:419-432.

Feng TP (1940) Studies on the neuromuscular junction XVIII. The local potentials around $n-m$ junctions induced by single and multiple volleys. Chin J Physiol 15:367-404.

Galarreta M, Hestrin S (1998) Frequency-dependent synaptic depression and the balance of excitation and inhibition in the neocortex. Nat Neurosci 1:587-594.

Kraushaar U, Jonas P (2000) Efficacy and stability of quantal GABA release at a hippocampal interneuron-principal neuron synapse. J Neurosci 20:5594-5607.

Kreitzer AC, Regehr WG (2000) Modulation of transmission during trains at a cerebellar synapse. J Neurosci 20:1348-1357.

Kusano K, Landau EM (1975) Depression and recovery of transmission at the squid giant synapse. J Physiol (Lond) 245:13-22.

Lachica EA, Rubsamen R, Rubel EW (1994) GABAergic terminals in nucleus magnocellularis and laminaris originate from the superior olivary nucleus. J Comp Neurol 348:403-418.

Lu T, Trussell LO (2000) Inhibitory transmission mediated by asynchronous transmitter release. Neuron 26:683-694.

Lundberg A, Quilisch H (1953) Presynaptic potentiation and depression of neuromuscular transmission in frog and rat. Acta Physiol Scand [Suppl iii] 30:111-120.

Markram H, Tsodyks M (1996) Redistribution of synaptic efficacy between neocortical pyramidal neurons. Nature 382:807-810.

Matveev V, Wang X (2000) Implications of all-or-none synaptic transmission and short-term depression beyond vesicle depletion: a computational study. J Neurosci 20:1575-1588.

Monsivais P, Yang L, Rubel EW (2000) GABAergic inhibition in nucleus magnocellularis: implications for phase locking in the avian auditory brainstem. J Neurosci 20:2954-2963.

O’Donovan MJ, Rinzel J (1997) Synaptic depression: a dynamic regulator of synaptic communication with varied functional roles. Trends Neurosci 20:431-433.

Otis TS, Trussell LO (1996) Inhibition of transmitter release shortens the duration of the excitatory synaptic current at a calyceal synapse. J Neurophysiol 76:3584-3588. 
Otis TS, Wu YC, Trussell LO (1996a) Delayed clearance of transmitter and the role of glutamate transporters at synapses with multiple release sites. J Neurosci 16:1634-1644.

Otis TS, Zhang S, Trussell LO (1996b) Direct measurement of AMPA receptor desensitization induced by glutamatergic synaptic transmission. J Neurosci 16:7496-7504.

Overholt EM, Rubel EW, Hyson RL (1992) A circuit for coding interaural time differences in the chick brainstem. J Neurosci 12:1698-1708.

Partin KM, Fleck MW, Mayer ML (1996) AMPA receptor flip/flop mutants affecting deactivation, desensitization, and modulation by cyclothiazide, aniracetam, and thiocyanate. J Neurosci 16:6634-6647.

Rahamimoff R, Yaari Y (1973) Delayed release of transmitter at the frog neuromuscular junction. J Physiol (Lond) 228:241-257.

Raman IM, Trussell LO (1992) The kinetics of the response to glutamate and kainate in neurons of the avian cochlear nucleus. Neuron 9:173-186.

Raman IM, Trussell LO (1995a) The mechanism of alpha-amino-3hydroxy-5-methyl-4-isoxazolepropionate receptor desensitization after removal of glutamate. Biophys J 68:137-146.

Raman IM, Trussell LO (1995b) Concentration-jump analysis of voltage-dependent conductances activated by glutamate and kainate in neurons of the avian cochlear nucleus. Biophys J 69:1868-1879.

Salvi RJ, Saunders SS, Powers NL, Boettcher FA (1992) Discharge patterns of cochlear ganglion neurons in the chicken. J Comp Physiol [A] 170:227-241.

Silver RA, Momiyama A, Cull-Candy SG (1998) Locus of frequencydependent depression identified with multiple-probability fluctuation analysis at rat climbing fibre-Purkinje cell synapses. J Physiol (Lond) 510:881-902.

Stevens CF, Wesseling JF (1998) Activity-dependent modulation of the rate at which synaptic vesicles become available to undergo exocytosis. Neuron 21:415-424.

Takeuchi A (1958) The long-lasting depression in neuromuscular transmission of frog. Jpn J Physiol 8:102-113.

Thies R (1965) Neuromuscular depression and the apparent depletion of transmitter in mammalian muscle. J Neurophysiol 28:427-442.

Trussell LO, Zhang S, Raman IM (1993) Desensitization of AMPA receptors upon multiquantal neurotransmitter release. Neuron 10:1185-1196.

Tsodyks MV, Markram H (1997) The neural code between neocortical pyramidal neurons depends on neurotransmitter release probability. Proc Natl Acad Sci USA 94:719-723.

Turecek R, Trussell LO (2000) Control of synaptic depression by glutamate transporters. J Neurosci 20:2054-2063.

Vyklicky Jr L, Patneau DK, Mayer ML (1991) Modulation of excitatory synaptic transmission by drugs that reduce desensitization at AMPA/ kainate receptors. Neuron 7:971-984.

Wang C, Zucker RS (1998) Regulation of synaptic vesicle recycling by calcium and serotonin. Neuron 21:155-167.

Wang LY, Kaczmarek LK (1998) High-frequency firing helps replenish the readily releasable pool of synaptic vesicles. Nature 394:384-388.

Warchol ME, Dallos P (1990) Neural coding in the chick cochlear nucleus. J Comp Physiol [A] 166:721-734.

Weis S, Schneggenburger R, Neher E (1999) Properties of a model of $\mathrm{Ca}^{2+}$-dependent vesicle pool dynamics and short term synaptic depression. Biophys J 77:2418-2429.

Wu LG, Borst JG (1999) The reduced release probability of releasable vesicles during recovery from short-term synaptic depression. Neuron 23:821-832.

Wu LG, Saggau P (1997) Presynaptic inhibition of elicited neurotransmitter release. Trends Neurosci 20:204-212.

Xu-Friedman MA, Regehr WG (1999) Presynaptic strontium dynamics and synaptic transmission. Biophys J 76:2029-2042.

Zhang S, Trussell LO (1994a) Voltage clamp analysis of excitatory synaptic transmission in the avian nucleus magnocellularis. J Physiol (Lond) 480:123-136.

Zhang S, Trussell LO (1994b) A characterization of excitatory postsynaptic potentials in the avian nucleus magnocellularis. J Neurophysiol 72:705-718.

Zhou N, Parks TN (1992) Developmental changes in the effects of drugs acting at NMDA or non-NMDA receptors on synaptic transmission in the chick cochlear nucleus (nuc. magnocellularis). Brain Res Dev Brain Res 67:145-152.

Zucker RS (1989) Short-term synaptic plasticity. Annu Rev Neurosci 12:13-31. 